\title{
Keeping adults physically active after Falls Management Exercise (FaME) programmes end: development of a physical activity maintenance intervention
}

\author{
Sarah Audsley ${ }^{* *}$ (D) Denise Kendrick' ${ }^{1}$ Pip Logan² and Elizabeth Orton ${ }^{1}$
}

\begin{abstract}
Background: Falls prevention exercise programmes help to improve muscle strength, balance and physical function, and reduce falling rates in older adults. Improvements in muscle strength, balance and physical function are reversed if older adults do not continue to be physically active after falls prevention exercise programmes end. This paper describes the design process of an intervention that aimed to maintain physical activity in older adults exiting falls prevention exercise programmes.

Methods: The development of the Keeping Adults Physically Active (KAPA) intervention and its implementation plan was guided by Bartholomew's Intervention Mapping approach. The intervention mapping approach involved (1) performing a needs assessment and developing intervention objectives using previous literature; (2) identifying theorybased intervention strategies from a systematic review and the National Institute of Clinical Excellence guidelines; and

(3) designing the KAPA intervention and its implementation plan with the guidance from an expert steering group.

Results: The KAPA intervention comprised of six group sessions of motivational interviewing, delivered monthly by trained and mentor-supported falls prevention practitioners. Intervention sessions lasted up to $90 \mathrm{~min}$ and were delivered in community settings over a 6-month duration. Participant manuals, illustrated exercise books, physical activity diaries and pedometers supported the KAPA intervention.

Conclusions: The intervention development process, consisting of Bartholomew's Intervention Mapping approach and the input from an expert steering group, was successful in creating the evidence-based KAPA intervention ready to be evaluated in a feasibility trial.
\end{abstract}

Keywords: Older adults, Physical activity, Falls prevention, Intervention development

\section{Introduction}

One third of adults aged over 65 years old, and half of adults aged over 80, fall each year and between 5 and $20 \%$ result in injury or hospitalisation [1-3]. In England, falls in older adults contribute to 255,000 emergency

\footnotetext{
* Correspondence: sarah.audsley_nottingham.uk.ac@outlook.com 'Division of Primary Care, University of Nottingham, Nottingham NG7 2RD, UK

Full list of author information is available at the end of the article
}

hospital visits yearly and an NHS annual spend of $£ 2.3$ billion in falls-related treatment [3-5]. Declines in physical activity results in cumulative muscle weakness, poor balance and physical impairments which markedly increase falls risk in older adults [6, 7]. To help improve health and physical function, the UK's Chief Medical Officers recommend that older people perform $150 \mathrm{~min}$ of moderate to vigorous physical activity (MVPA) and two strength and balance exercise sessions weekly [8].

(c) The Author(s). 2021 Open Access This article is licensed under a Creative Commons Attribution 4.0 International License, which permits use, sharing, adaptation, distribution and reproduction in any medium or format, as long as you give appropriate credit to the original author(s) and the source, provide a link to the Creative Commons licence, and indicate if changes were made. The images or other third party material in this article are included in the article's Creative Commons licence, unless indicated otherwise in a credit line to the material. If material is not included in the article's Creative Commons licence and your intended use is not permitted by statutory regulation or exceeds the permitted use, you will need to obtain permission directly from the copyright holder. To view a copy of this licence, visit http://creativecommons.org/licenses/by/4.0/. The Creative Commons Public Domain Dedication waiver (http://creativecommons.org/publicdomain/zero/1.0/) applies to the data made available in this article, unless otherwise stated in a credit line to the data. 
Physical, mental and social independence is retained when older adults autonomously remain active [9]. Yet, recent estimations show that $13 \%$ of men and $10 \%$ of women over 65 years old, and less than $5 \%$ of people over 75, meet the physical activity guidelines [10].

Falls prevention exercise programmes that target strength and balance exercise have been shown to reduce falling rates in older adults by $21 \%[11,12]$. However, longitudinal research findings suggest that older adults rarely maintain physical activity beyond 12 months after exercise programmes such as these end [13-16]. As a result, over time improvements in strength and balance are lost, and falls risk increases. The results of randomised controlled trials suggest that behaviour change interventions can help motivate older people to keep active after general physical activity promotion programmes end [17-29], but there is less certainty about whether physical activity can be maintained following specialised falls prevention exercise programmes [30-32].

The Falls Management Exercise (FaME) programme is a structured evidence-based exercise class that contains age appropriate exercises for older adults [16]. The ProAct $65+$ trial found that an increased proportion of participants achieved $150 \mathrm{~min}$ of MVPA weekly in response to FaME [16]. Yet, the longitudinal findings showed that between 12 and 24 months after FaME classes came to an end the proportion of people meeting the MVPA target decreased, and $15.5 \%$ performed no minutes of MVPA weekly [16]. Additionally, research findings suggest that physical activity maintenance interventions may be ineffective in helping maintain physical activity increases after falls prevention exercise programmes end [30-33].

Currently, it is unknown what strategies would best maintain physical activity in older people exiting FaME programmes. This suggests that an intervention is needed to help educate, motivate and support older adults to remain physically active after FaME programmes end. The aim of this study was to develop an evidenced-based physical activity maintenance intervention. The intervention aimed to help older adults continue performing $150 \mathrm{~min}$ of MVPA, and two sessions of strength and balance exercise, per week after the completion of the FaME programme. The intervention developed was called Keeping Adults Physically Active (KAPA) and was delivered by 10 postural stability instructors to 50 FaME programme users attending 8 classes in Derby City, Leicestershire and Rutland. This paper describes the step-wise process of developing the evidence-based KAPA intervention.

\section{Methods}

Bartholomew's Intervention Mapping approach systematically integrates behaviour determinants, theory and research findings to develop interventions and their implementation and evaluation plans [34, 35]. The development of the KAPA intervention and its implementation plan was guided by the iterative six-step intervention mapping approach, as outlined in Fig. 1 [34, 35]. The findings of a literature review, previous qualitative research, government guidelines and an expert steering group supported the KAPA intervention development process [32].

\section{Step 1: needs assessment}

Step 1 involved (i) identifying the problem and justifying the need for the KAPA intervention and (ii) identifying the determinants surrounding physical activity maintenance in falls prevention exercise programme completers. Justifying the interventions need was outlined in the introduction and will not be further discussed here. The determinants surrounding physical activity maintenance in FaME completers were identified in an ongoing study by the same research team (the Keeping Active study). The Keeping Active Study assessed both non-modifiable (i.e. demographic information) and modifiable (i.e. behavioral) determinants to physical activity maintenance in 30 older adults who had completed falls prevention exercise programmes, including the FaME programme $[36,37]$. The study used semi-structured interviews to explore the barriers and facilitators for physical activity maintenance. The results suggested that factors surrounding motivation, self-efficacy autonomy, enjoyment, positive feedback, positive evaluation of physical activity (i.e. physical benefits and social interaction) and the development of habitual physical activity behaviours promoted physical activity maintenance [37]. The KAPA intervention was based solely on these modifiable determinants. These findings were used to help develop the KAPA intervention by extracting, tabulating and categorising the physical activity determinants into themes of physical, psychological, environmental and social factors. This formed the foundations of the matrix table on which the KAPA intervention was created (see Supplementary material 1, column 1 of the intervention matrix table).

\section{Step 2: identification of the intervention objectives}

In step 2, the researchers correlated the physical activity determinants with potential solutions at participant level to support physical activity maintenance (i.e. performance objectives). For each physical activity determinant a performance objective was identified by asking the question "what do the participants need to do to affect this determinant?" [38]. Each performance objective was added onto the matrix. In order to identify the changes needed at provider level (i.e. change objectives) the question was asked "what do the service providers need to do to promote participant change?". For example, developing new physical activity routines and habits was a physical activity determinant recognised in the Keeping 


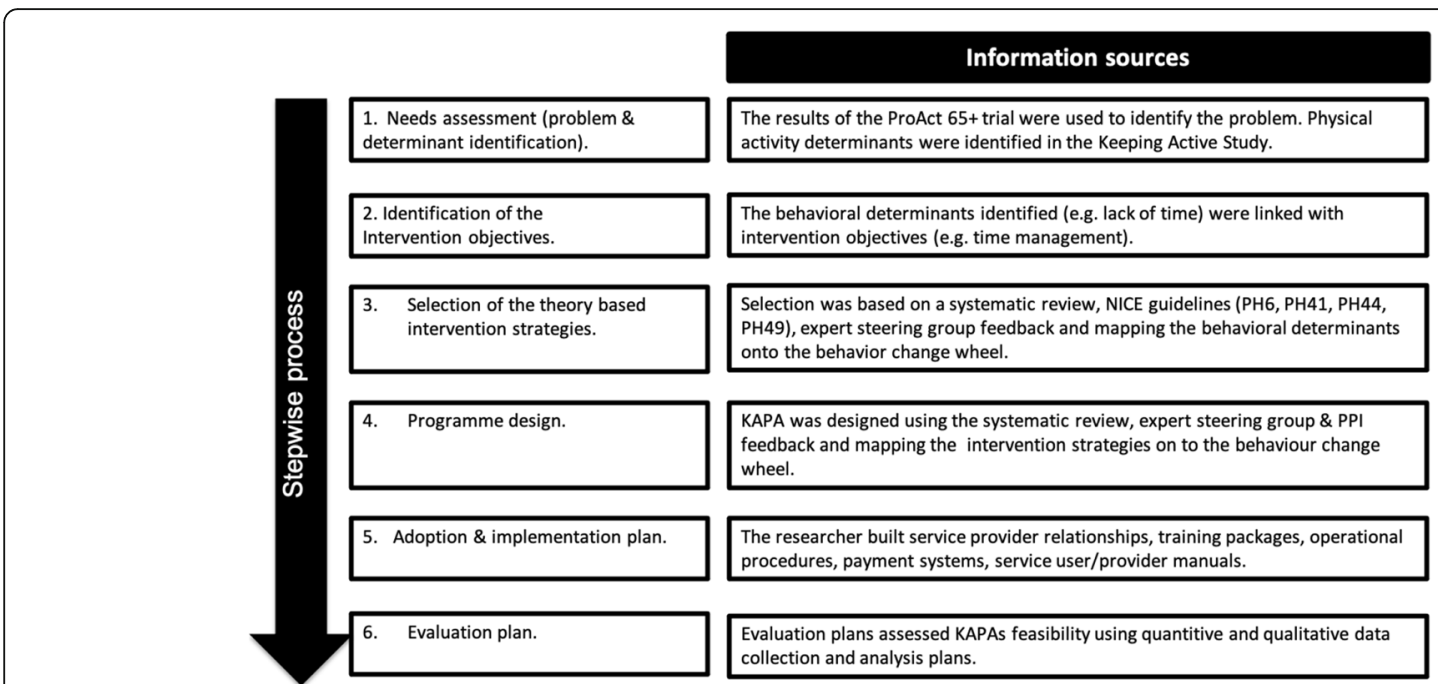

Fig. 1 Development of the KAPA intervention using Bartholomew's Intervention Mapping Approach. Based on the steps of Intervention Mapping Framework [35] Footnote: NICE—National Institute for Health and Care Excellence, PPI_People \& Public Involvement

Active Study [37]. The performance objective mapped to this determinant was for participants to "repeatedly perform new physical activity behaviours to help create new habits". Whereas, the change objective was for service providers to "facilitate the development of behaviour repetition and relapse and prevention plans". Performance and change objectives were mapped against each physical activity determinant on the matrix (Supplementary material 1 , column $2 \& 3$ of the intervention matrix table). This step was important to ensure that actions to effect change were identified in order to achieve the desired intervention outcomes.

\section{Step 3: selection of theory-based intervention strategies}

The goal of step three was to identify appropriate theory-based intervention strategies to achieve the intervention objectives. During this stage, a behaviour change theory and its associated intervention strategies were chosen to underpin the intervention. There is currently a lack of evidence supporting specific behaviour change theories for physical activity maintenance in older adults [39]. Hence, the behaviour change wheel was chosen as it incorporates multiple behaviour change theories [40, 41]. The behaviour change wheel categorises the opportunity, capability and motivation of specific populations to perform a given behaviour, otherwise known as the COM-B analysis. The COM-B analysis is centred at the core of the wheel and links to the intervention functions on the wheels next layer. The intervention functions most likely to evoke change are then selected. The intervention functions contain a mix of relevant behaviour change techniques (aka the behaviour change wheel's intervention strategies) which are the "active components" that support individuals in making a behaviour change [40, 42].

The physical activity determinants identified in the Keeping Active Study were categorised into the COM-B. This was then used to identify the intervention functions and behaviour change techniques (BCTs) on the behaviour change wheel [41]. All BCTs identified during this process were added onto the matrix of behaviour determinants, performance and change objectives (see Supplementary material 1, column 4 of the intervention matrix table).

\section{Step 4: programme design}

The fourth step involved specifying, planning and organising the KAPA intervention. This included specifying the BCTs, delivery modes, training package and resources. It was important that the KAPA intervention was evidence based and acceptable to both the service providers and participants. An expert steering group was formed consisting of seven local authority physical activity service managers, nine postural stability instructors and a sports development officer. To help improve the feasibility, acceptability and operationalisation of the KAPA intervention the group provided feedback and guidance during the intervention development process using an informal consensus approach.

Effective BCTs and delivery modes were identified in the literature base (i.e. KAPAs underpinning systematic review [33], a systematic review on behaviour maintenance [43] and the National Institute for Clinical Excellence (NICE) guidelines for physical activity and behaviour change (PH6, PH41, PH44, PH49) [44-47]. These were highlighted as potential BCTs on the matrix table. See Table 1 which shows the evidence based BCT's chosen. 


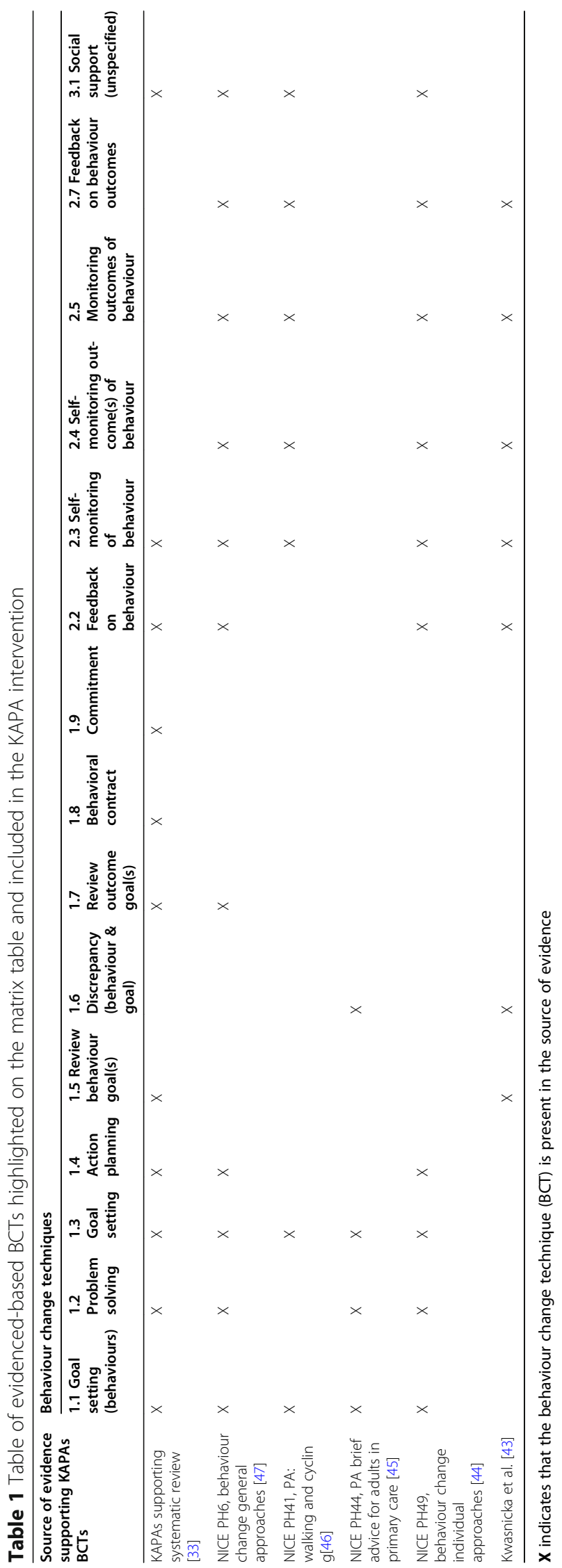




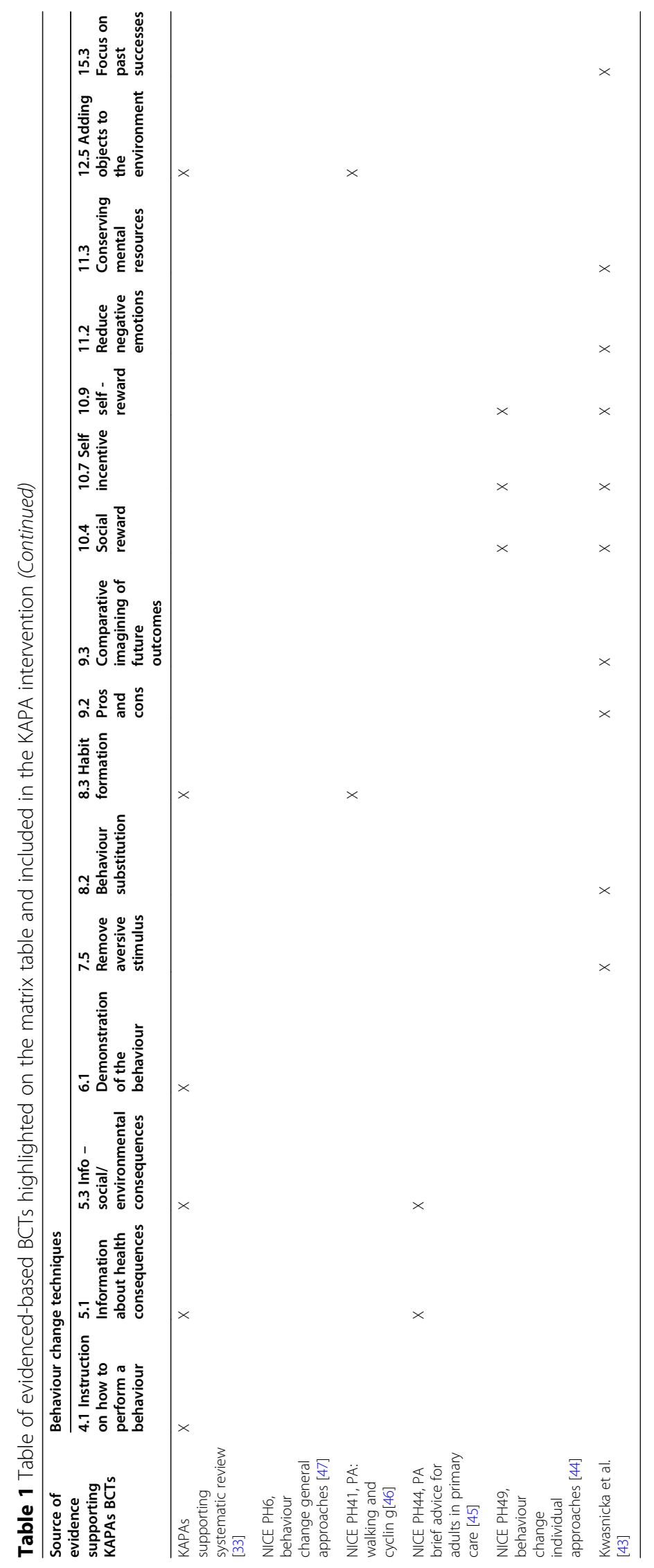


An intervention framework, detailing potential BCTs and delivery methods, was developed using evidence from KAPA's underpinning systematic review and NICE guidelines (Fig. 2) [5, 44, 45, 47]. In brief, the systematic review suggested that interventions were effective when delivered on a monthly or quarterly basis over a period of 6 months or more. Interventions delivered via multimodal communication methods and a motivational interviewing approach were often effective. As were interventions supported by pedometers, exercise equipment and illustrative exercise sheets. NICE guidelines for physical activity also advocate the use of pedometers, monitoring and goal setting [45]. NICE guidelines for behaviour change recommend that staff should be adequately trained and mentors should support staff implementing interventions [44]. All information was depicted in the intervention framework and presented at two expert steering group meetings. Decisions surrounding the potential effectiveness, acceptability and the feasibility of operationalising each BCT and intervention delivery mode was agreed by the expert steering group and used to shape the final intervention (see Table 2).

\section{Step 5: adoption and implementation plan}

Once the KAPA intervention was finalised, the next step was to develop an implementation plan. The intervention was operationalised by first developing the syllabus for the KAPA training programme. The training content related to the background knowledge and practical skills needed to deliver the KAPA intervention. The training resources included a trainee handbook, lecture slides, case studies and data collection forms. The training was delivered face to face over seven-hours in a group setting. A physiotherapist experienced in delivering physical activity programmes mentored individual postural stability instructors at their place of work. Mentoring sessions were provided at the postural stability instructors request and lasted between 30 and $45 \mathrm{~min}$.

The standard operating procedure document was developed to outline the content and procedures of each of the six KAPA intervention sessions. Postural stability instructors were encouraged to refer back to the standard operating procedures before delivering each session to help improve fidelity. A participant manual was created and given to each participant to help guide them through the KAPA intervention. Many BCTs included in the KAPA intervention were similar to those delivered in England's NHS Health Trainer service. Therefore, the NHS Health Trainer Handbook was used as a source of reference when developing the training syllabus, standard operating procedures and participant handbook [48].

\section{Step 6: generating an intervention evaluation plan} The final step was to generate an evaluation plan for the intervention. The feasibility of delivering the KAPA intervention was evaluated in a mixed-methods cluster randomised controlled feasibility study which evaluated recruitment, retention and attendance rates, selfreported physical activity and the feasibility and acceptability of the KAPA intervention. Details of the feasibility study methods and results are published elsewhere [49].

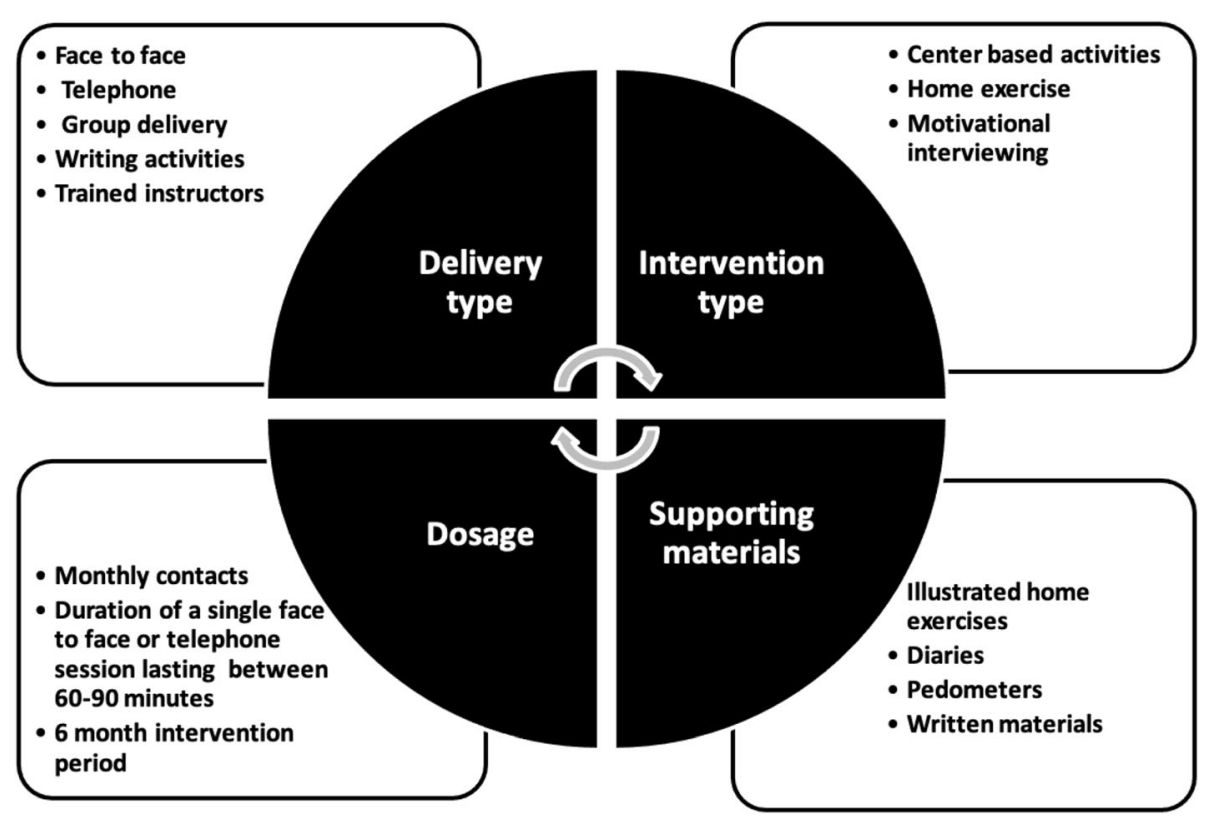

Fig. 2 KAPA intervention framework developed from the systematic review and the NICE guidelines 
Audsley et al. Pilot and Feasibility Studies

(2021) 7:108

Page 7 of 12

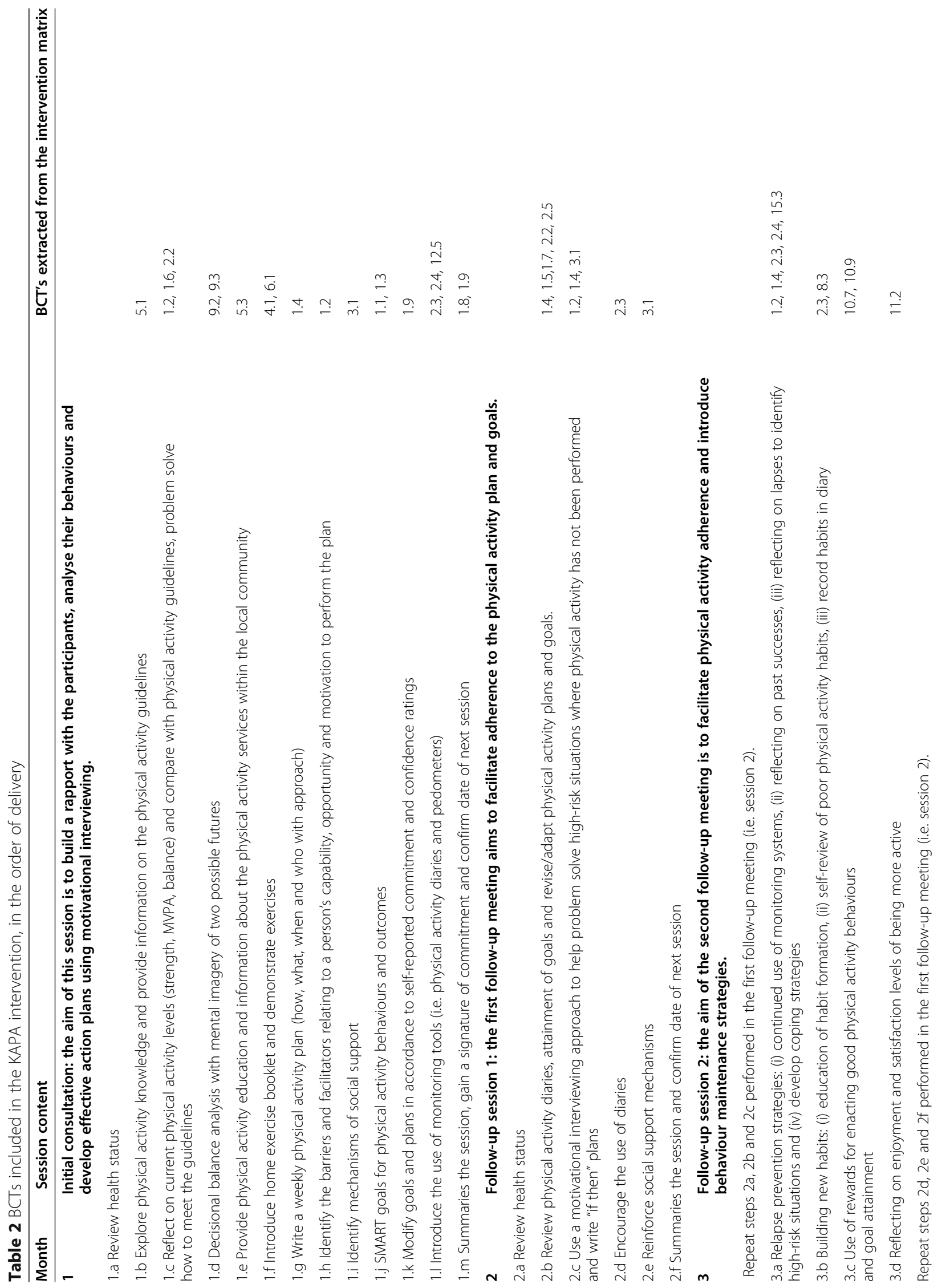




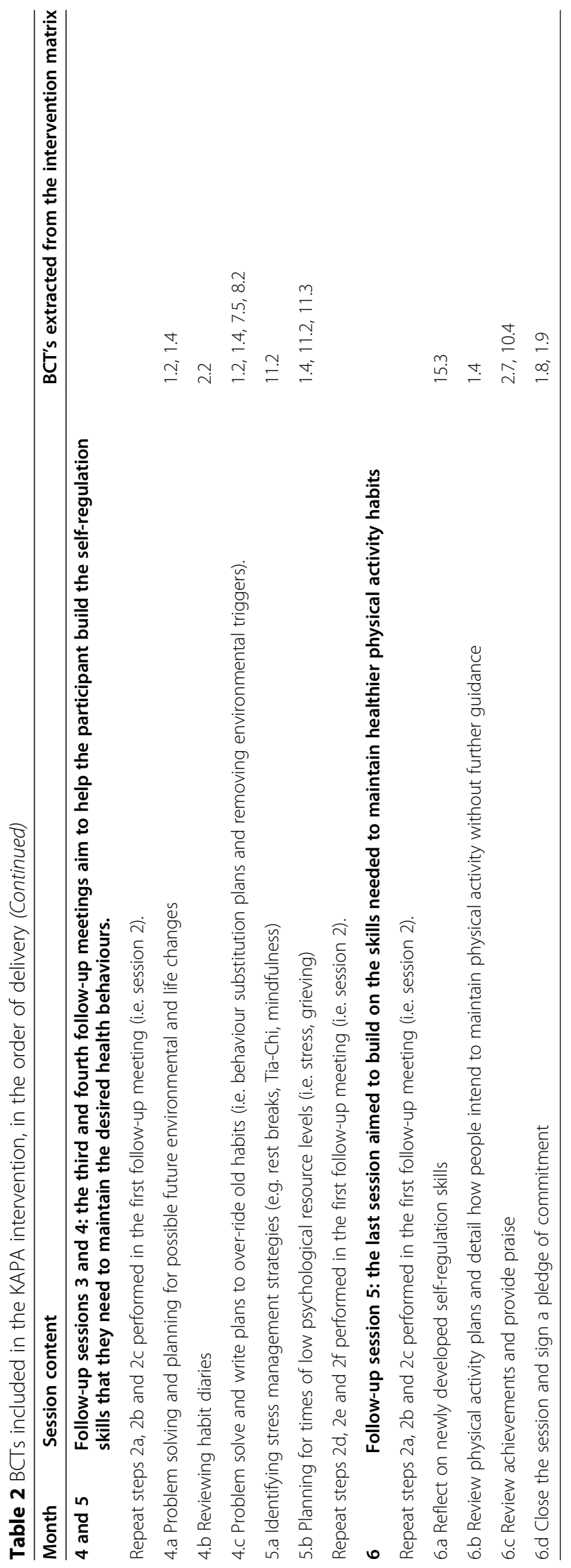




\section{Results}

\section{KAPA intervention}

Older adults exiting a 24-week FaME programme received six sessions of motivational interviewing over a 6month period. Group sessions, aiming to provide social opportunities, lasted between 60 and $90 \mathrm{~min}$ and were delivered in accessible community-based venues. Participants unable to attend group sessions received the KAPA intervention via telephone.

KAPA participants were given a written resource containing information about locally available physical activity opportunities (e.g. age appropriate exercise classes, walking groups, racket sports, bowling), an illustrated postural stability exercise booklet (from Later Life Training) and information on lifestyle physical activity. Participants were given infographics explaining the UK's Chief Medical Officers' physical activity guidelines for adults. The guidelines define MVPA as being breathless, but still able to talk. The infographics depict different types of exercises that could result in MVPA (e.g. walking, cycling, swimming) and strength and balance exercise (e.g. resistance training, carrying shopping, bowls, yoga). Participants used the infographics to create a plan to meet the government recommendations of performing 150 min of MVPA and two sessions of strength and balance exercise weekly. Participants set physical activity goals and were encouraged to monitor their progress towards these by completing physical activity diaries and monitoring step count via pedometers.

The purpose of the second and subsequent sessions was to review physical activity diaries and provide feedback on goal attainment. Various BCTs were delivered throughout each of the six sessions to help support participants in continuing to be active (BCTs are outlined in Table 2). BCTs aimed to resolve ambivalence about remaining active, encourage adherence to the KAPA intervention and build the self-regulation skills needed to maintain physical activity habits. The precise detail of each of the six KAPA sessions can be viewed in the participant handbook provided in Supplementary material 2.

\section{Discussion}

Summary of the KAPAs intervention development process The resultant intervention is a motivational interviewing programme aimed to help older adults remain physically active after the completion of the 24-week FaME programme. In line with the Chief Medical Officer's guidance for physical activity, KAPAs primary goal was to support participants to achieve $150 \mathrm{~min}$ of moderate to vigorous physical activity (MVPA) and two sessions of strength and balance exercise per week [50]. We agree with the views of other intervention mapping users that the approach is useful in transparently building evidence-based interventions [51-56].

\section{Comparison with the previous literature}

The results reported in KAPA systematic review suggest that physical activity maintenance interventions are ineffective in helping older adults exiting falls prevention exercise programmes to stay active [33]. Booster letters and review days delivered after an initial "hip fracture prevention" programme resulted in no significant differences in the proportion of participants who kept active for more than 30 min per week 2 years after the intervention ended [31]. Reductions in physical activity at 9-month follow-up were seen in another study that integrated unspecified relapse and prevention strategies into a fall's prevention exercise programme [32]. Brief advice on remaining active after the completion of a falls programme did not result in physical activity levels being maintained at 9 or 12months post-intervention [30].

KAPA differs from these previous interventions as it contains 6 sessions of postural stability instructor delivered motivational interviewing, supported by workbooks, goal setting, social opportunities and physical activity monitoring tools. Although no study has investigated these strategies for physical activity maintenance in fallsprevention exercise programme users, many have shown motivational interviewing [13, 18, 22, 24-26], physical activity monitoring tools, goal setting [13, 17-29, 57-60] and social support [28, 61-65] to help older adults remain active. This suggests that the KAPA intervention has the potential to help FaME programme users remain active. Certainly, the participants in the KAPA feasibility study reported that the peer support, exercise booklets and physical activity monitoring tools encouraged them to keep active [49]. However, a full-scale trial is needed to assess whether KAPA could significantly maintain physical activity increases after FaME programmes end.

\section{Strengths and limitations}

Bartholomew's Intervention Mapping approach is a systematic way of linking determinants, theory and intervention strategies to help develop a comprehensive evidence and theory-based intervention. The individual steps ensured that the development process was methodical, logical and transparent. Yet, a limitation of Bartholomew's Intervention Mapping approach is that the application of each step is flexible, diverse and open to interpretation [52, 54, 55, 66-68]. Therefore, others may have gone through the same process and reached different conclusions on KAPAs intervention content.

In stage 1, it is common for researchers to collect qualitative information on behavioural determinants using service user focus groups and interviews $[54,55]$. The data collected within the Keeping Active Study filled this void when developing the KAPA intervention as the physical activity determinants directly related to maintaining physical activity in older people exiting falls 
prevention exercise programmes. However, the needs of the participants in the ProAct $65+$ trial maybe different to those taking part in local authority delivered FaME classes. Therefore, the physical activity determinants may have differed between the two participant groups and not all the determinants included may be relevant to the KAPA intervention.

During stage 2, the research team brainstormed a list of intervention objectives. It should be recognised that service users nor the expert steering group were included in this process. There are important distinctions between researcher, service user and provider perspectives. Thus, valuable service user and provider insights were likely missed which may have led to errors in identifying the most appropriate intervention objectives.

During stage 3, an intervention framework was created containing a simplified version of the evidence-based BCTs to help support the intervention development and refinement stage with the expert steering group. The expert steering group meetings were an integral part of KAPA's development as the input from the expert steering group helped to ensure that the intervention was feasible and acceptable to deliver within each separate local authority. This was a particular strength as without the steering group's input the intervention developed may not have been feasible to deliver. However, the steering groups involvement could have been strengthened by employing a nominal group approach, such as voting, over an informal consensus method, as this would have helped to quantify the level of agreement during the intervention development process [69].

During stage 4 , the aim was to include BCTs to address each performance and change objective. It was outside the KAPA interventions scope to deliver BCTs for all the behaviour determinants identified. For example, it would have been difficult to address the socioecological behaviour mediators such as transport provision or to improve people's memory. Addressing these determinants would require collaboration with many different types of services and professionals. Thus, KAPA's intervention effectiveness maybe limited by not being able to provide resolutions for these determinants. Future interventions may benefit from including collaborators across multiple professions to help tackle issues that could limit intervention effectiveness.

\section{Implications for policy, practice and future research}

The process of developing interventions in research and clinical practice has been criticised for its lack of conceptualisation and planning [70]. Failing to link behaviour determinants with appropriate theoretically based intervention strategies may in part explain the mixed outcomes of prior interventions [67]. Although Bartholomew's Intervention Mapping approach is complex and resource and time intensive, researchers and practitioners would still benefit from using this transparent, responsive and systematic approach to help develop interventions with good scientific rigor [52, 70].

Reporting the intervention development process helps researchers, practitioners and policy makers to better understand the underpinning rationale, decision making processes and the methods used in developing interventions [71]. Publishing intervention development processes is integral to help to improve the transparency of the methodological rigor taken in developing interventions and can help practitioners and policy-makers assess whether pre-made interventions meet service-user needs [52, 71].

\section{Conclusion}

Bartholomew's Intervention Mapping approach provided a systematic framework to support the development of the KAPA intervention. The behaviour change wheel aided the mapping of evidenced-based BCTs onto the intervention matrix to help ensure that KAPA's intervention components were appropriate to encourage older adults to remain active. The expert steering groups guidance was integral in shaping an intervention that was feasible for the postural stability instructors to deliver and acceptable for the FaME users to receive. The intervention development process was successful in developing an intervention ready to be evaluated in a feasibility trial. A full-scale randomised controlled trial is needed to assess whether the KAPA intervention is clinically effective in helping older adults remain active after the completion of FaME.

\section{Abbreviations}

BCTs : Behaviour Change Techniques; FaME : Falls Management Exercise; KAPA: Keeping Adults Physically Active; MVPA: Moderate to Vigorous Physical Activity

\section{Supplementary Information}

The online version contains supplementary material available at https://doi. org/10.1186/s40814-021-00844-w.

Additional file 1: Supplementary material 1. Matrix of behaviour determinants, performance and change objectives and behaviour change techniques (BCTs).

Additional file 2: Supplementary material 2. Participant Handbook

\section{Acknowledgements \\ We would like to say a special thanks to the expert steering group who aided the development of the KAPA intervention.}

Authors' contributions

SA led on the intervention design, set up and managed the expert steering group meetings, interpreted the data and drafted the manuscript. EO, DK and $\mathrm{PL}$ contributed to the intervention design, interpretation of data and revision of the manuscript. EO was the study chief investigator. All authors read and approved the final manuscript. 


\section{Funding}

This article presents independent research funded by the University of Nottingham and the National Institute for Health Research School of Primary Care Research. The views expressed are those of the author(s) and not necessarily those of the NIHR, NHS or the Department of Health.

\section{Availability of data and materials}

The datasets used (i.e. intervention matrix table and participant handbook) are included in the Supplementary materials 1 and 2 .

\section{Declarations}

Ethics approval and consent to participate

Not applicable.

\section{Consent for publication}

Not applicable.

\section{Competing interests}

The authors declare that they have no competing interests.

\section{Author details}

'Division of Primary Care, University of Nottingham, Nottingham NG7 2RD, UK. ${ }^{2}$ Division of Rehabilitation, Ageing and Wellbeing, University of Nottingham, Nottingham NG7 2RD, UK.

Received: 17 August 2019 Accepted: 28 April 2021

Published online: 15 May 2021

\section{References}

1. Campbell AJ, Reinken J, Allan BC, Martinez GS. Falls in old age: a study of frequency and related clinical factors. Age Ageing. 1981;10(4):264-70. https://doi.org/10.1093/ageing/10.4.264.

2. O'Loughlin JL, Robitaille Y, Boivin JF, Suissa S. Incidence of and risk factors for falls and injurious falls among the community-dwelling elderly. Am J Epidemiol. 1993; 137(3):342-54. https://doi.org/10.1093/oxfordjournals.aje.a116681.

3. Rubenstein LZ. Falls in older people: epidemiology, risk factors and strategies for prevention. Age Ageing. 2006;35(Suppl 2):ii37-41.

4. Public Health England. Falls and fracture consensus statement: supporting commissioning for prevention. London: Department of Health; 2017.

5. National Institute for Health and Clinical Excellence (NICE). Physical activity: exercise referral schemes [NICE guideline PH54]. London: NICE; 2014

6. World Health Organization (WHO). WHO global report on falls prevention in older age. Geneva: WHO; 2008

7. Lloyd BD, Williamson DA, Singh NA, et al. Recurrent and injurious falls in the year following hip fracture: a prospective study of incidence and risk factors from the Sarcopenia and Hip Fracture study. J Gerontol A Biol Sci Med Sci. 2009;64(5):599-609.

8. Chief Medical Officer. Stay active: a report on physical activity for health from the four home countries. London: Department of Health; 2011.

9. Vagetti GC, Barbosa Filho VC, Moreira NB, Oliveira V, Mazzardo O, Campos W. Association between physical activity and quality of life in the elderly: a systematic review, 2000-2012. Br J Psychiatry. 2014;36(1):76-88. https://doi. org/10.1590/1516-4446-2012-0895.

10. National Digital Health Survey for England 2016 physical activity in adults. 2016. http://healthsurvey.hscic.gov.uk/media/63730/HSE16-Adult-phy-act.pdf (Accessed 08 May 2019).

11. Sherrington C, Michaleff ZA, Fairhall N, Paul SS, Tiedemann A, Whitney J, et al. Exercise to prevent falls in older adults: an updated systematic review and meta-analysis. Br J Sports Med. 2017;51(24):1750-8. https://doi.org/1 0.1136/bjsports-2016-096547.

12. Gillespie LD, Robertson MC, Gillespie WJ, et al. Interventions for preventing falls in older people living in the community. Cochrane Database Syst Rev. 2012;9:CD007146.

13. Hobbs N, Godfrey A, Lara J, et al. Are behavioral interventions effective in increasing physical activity at 12 to 36 months in adults aged 55 to 70 years? A systematic review and meta-analysis. BMC Med. 2013;11:75.

14. Iliffe S, Kendrick D, Morris R, Skelton D, Gage H, Dinan S, et al. Multi-centre cluster randomised trial comparing a community group exercise programme with home based exercise with usual care for people aged 65 and over in primary care: protocol of the ProAct 65+ trial. Trials. 2010;11(1): 6. https://doi.org/10.1186/1745-6215-11-6.

15. Pavey TG, Taylor AH, Fox KR, Hillsdon M, Anokye N, Campbell JL, et al. Effect of exercise referral schemes in primary care on physical activity and improving health outcomes: systematic review and meta-analysis. BMJ. 2011:343(nov04 2):d6462. https://doi.org/10.1136/bmi.d6462.

16. Iliffe $S$, Kendrick D, Morris $R$, et al. Multicentre cluster randomised trial comparing a community group exercise programme and home-based exercise with usual care for people aged 65 years and over in primary care. Health Technol Assess. 2014;18(49):vii-xxvii 1-105.

17. Voukelatos A, Merom D, Sherrington C, Rissel C, Cumming RG, Lord SR. The impact of a home-based walking programme on falls in older people: the easy steps randomised controlled trial. Age Ageing. 2015;44(3):377-83. https://doi.org/10.1093/ageing/afu186.

18. von Bonsdorff MB, Leinonen R, Kujala UM, Heikkinen E, TÃ 9 rmÃ akangas T, Hirvensalo $M$, et al. Effect of physical activity counseling on disability in older people: a 2-year randomized controlled trial. J Am Geriatr Soc. 2008; 56(12):2188-94. https://doi.org/10.1111/j.1532-5415.2008.02000.x.

19. Teri L, McCurry SM, Logsdon RG, Gibbons LE, Buchner DM, Larson EB. A randomized controlled clinical trial of the Seattle protocol for activity in older adults. J Am Geriatr Soc. 2011;59(7):1188-96. https://doi.org/10.1111/j.1 532-5415.2011.03454.x

20. Rydwik E, Lammes E, Frandin K, Akner G. Effects of a physical and nutritional intervention program for frail elderly people over age 75. A randomized controlled pilot treatment trial. Aging Clin Exp Res. 2008;20(2):159-70. https://doi.org/10.1007/BF03324763.

21. Pahor M, Blair SN, Espeland M, et al. Effects of a physical activity intervention on measures of physical performance: Results of the lifestyle interventions and independence for Elders Pilot (LIFE-P) study. J Gerontol A Biol Sci Med Sci. 2006:61(11):1157-65.

22. Opdenacker J, Boen F, Coorevits N, Delecluse C. Effectiveness of a lifestyle intervention and a structured exercise intervention in older adults. Prev Med. 2008;46(6):518-24. https://doi.org/10.1016/j.ypmed.2008.02.017.

23. Luten KA, Reijneveld SA, Dijkstra A, de Winter AF. Reach and effectiveness of an integrated community-based intervention on physical activity and healthy eating of older adults in a socioeconomically disadvantaged community. Health Educ Res. 2016;31(1):98-106. https://doi.org/10.1093/her/ cyv064.

24. Jancey JM, Lee AH, Howat PA, Burke L, Leong CC, Shilton T. The effectiveness of a walking booster program for seniors. Am J Health Promot. 2011;25(6):363-7. https://doi.org/10.4278/ajhp.090512-ARB-164.

25. Harris T, Kerry SM, Victor CR, Ekelund U, Woodcock A, lliffe $S$, et al. A primary care nurse-delivered walking intervention in older adults: PACE (pedometer accelerometer consultation evaluation)-Lift cluster randomised controlled trial. PLoS Med. 2015;12(2):e1001783. https://doi.org/10.1371/journal.pmed.1 001783

26. Elley CR, Kerse N, Arroll B, Robinson E. Effectiveness of counselling patients on physical activity in general practice: cluster randomised controlled trial. BMJ. 2003;326(7393):793. https://doi.org/10.1136/bmj.326.7393.793.

27. Duru OK, Sarkisian CA, Leng M, Mangione CM. Sisters in motion: a randomized controlled trial of a faith-based physical activity intervention. J Am Geriatr Soc. 2010;58(10):1863-9. https://doi.org/10.1111/j.1532-5415.201 0.03082.x.

28. Dubbert PM, Cooper KM, Kirchner KA, Meydrech EF, Bilbrew D. Effects of nurse counseling on walking for exercise in elderly primary care patients. $J$ Gerontol A Biol Sci Med Sci. 2002;57(11):M733-40. https://doi.org/10.1093/ gerona/57.11.M733.

29. Buman MP, Giacobbi PR Jr, Dzierzewski JM, et al. Peer volunteers improve long-term maintenance of physical activity with older adults: a randomized controlled trial. J Phys Act Health. 2011:8(Suppl 2):S257-66. https://doi.org/1 0.1123/jpah.8.s2.s257

30. Swanenburg J, de Bruin ED, Stauffacher M, Mulder T, Uebelhart D. Effects of exercise and nutrition on postural balance and risk of falling in elderly people with decreased bone mineral density: randomized controlled trial pilot study. Clin Rehabil. 2007;21(6):523-34. https://doi.org/10.1177/026921 5507075206.

31. Pekkarinen T, Loyttyniemi E, Valimaki M. Hip fracture prevention with a multifactorial educational program in elderly community-dwelling Finnish women. Osteoporos Int. 2013;24(12):2983-92.

32. Laforest S, Pelletier A, Gauvin L, Robitaille Y, Fournier M, Corriveau H, et al. Impact of a community-based falls prevention program on maintenance of 
physical activity among older adults. J Aging Health. 2009;21(3):480-500 https://doi.org/10.1177/0898264308328988.

33. Audsley S. Keeping adults physically active intervention development and randomised controlled feasibility study. Nottingham: University of Nottingham; 2019.

34. Yardley L, Ainsworth B, Arden-Close E, Muller I. The person-based approach to enhancing the acceptability and feasibility of interventions. Pilot Feasibility Stud. 2015;1(1):37. https://doi.org/10.1186/s40814-015-0033-z.

35. Bartholomew LK, Parcel GS, Kok G. Intervention mapping: a process for developing theory- and evidence-based health education programs. Health Educ Behav. 1998;25(5):545-63. https://doi.org/10.1177/109019819802 500502.

36. Kendrick D, Orton E, Lafond N, Audsley S, Maula A, Morris R, et al. Keeping active: maintenance of physical activity after exercise programmes for older adults. Public Health. 2018;164:118-27. https://doi.org/10.1016/.jpuhe.2018.08.003.

37. Maula A, LaFond N, Orton E, lliffe S, Audsley S, Vedhara K, et al. 'Use it, or lose it': maintenance of physical activity post participation in a strength and balance training programme for older adults. A qualitative study. BMC Geriatr. 2019;19(1):349. https://doi.org/10.1186/s12877-019-1366-x.

38. Dalum P, Schaalma H, Kok G. The development of an adolescent smoking cessation intervention--an intervention mapping approach to planning. Health Educ Res. 2012;27(1):172-81. https://doi.org/10.1093/her/cyr044.

39. Zubala A, MacGillivray S, Frost H, Kroll T, Skelton DA, Gavine A, et al. Promotion of physical activity interventions for community dwelling older adults: a systematic review of reviews. PLoS One. 2017;12(7):e0180902. https://doi.org/10.1371/journal.pone.0180902.

40. Michie S, van Stralen MM, West R. The behaviour change wheel: a new method for characterising and designing behaviour change interventions. Implement Sci. 2011;6(1):42. https://doi.org/10.1186/1748-5908-6-42.

41. Michie $S$, Atkins L, West R. The behaviour change wheel: a guide to designing interventions. Great Britain: Silverback Publishing; 2014.

42. Michie S, Johnston M, Abraham C, Lawton R, Parker D, Walker A, et al. Making psychological theory useful for implementing evidence based practice: a consensus approach. Qual Saf Health Care. 2005;14(1):26-33. https://doi.org/10.1136/qshc.2004.011155.

43. Kwasnicka D, Dombrowski SU, White M, Sniehotta F. Theoretical explanations for maintenance of behaviour change: a systematic review of behaviour theories. Health Psychol Rev. 2016;10(3):277-96. https://doi.org/1 0.1080/17437199.2016.1151372.

44. National Institute for Health and Clinical Excellence. Behaviour change at population, community and individual levels. London: NICE; 2007.

45. National Institute for Health and Clinical Excellence. Physical activity: brief advice for adults in primary care. London: NICE; 2013.

46. National Institute for Health and Clinical Excellence. Physical activity: walking and cycling. London: NICE; 2012.

47. National Institute for Health and Clinical Excellence. Behaviour change: general approaches. London: NICE; 2007.

48. Michie S, Rumsey N, Fussell A, et al. Improving health: changing behaviour. In: Department-of-Health, editor. NHS health trainer handbook. London: Crown; 2008.

49. Audsley $S$, Kendrick D, Logan P, Jones M, Orton E. A randomised feasibility study assessing an intervention to keep adults physically active after falls management exercise programmes end. Pilot Feasibility Stud. 2020;6(1):37 https://doi.org/10.1186/s40814-020-00570-9.

50. World Health Organization (WHO). Global recommendations on physical activity for health. Geneva: WHO; 2010.

51. Ammendolia C, Cassidy D, Steensta I, et al. Designing a workplace return-towork program for occupational low back pain: an intervention mapping approach. BMC Musculoskelet Disord. 2009;10(1):65. https://doi.org/10.11 86/1471-2474-10-65.

52. Kok G, Gottlieb NH, Peters GJ, et al. A taxonomy of behaviour change methods: an Intervention Mapping approach. Health Psychol Rev. 2016; 10(3):297-312. https://doi.org/10.1080/17437199.2015.1077155.

53. Kok G, Lo S, Peters G, Ruiter R. Changing energy-related behavior: An Intervention Mapping approach. Energy Policy. 2011;39(9):5280-6. https:// doi.org/10.1016/j.enpol.2011.05.036.

54. McEachan RR, Lawton RJ, Jackson C, Conner M, Lunt J. Evidence, theory and context: using intervention mapping to develop a worksite physical activity intervention. BMC Public Health. 2008:8(1):326. https://doi.org/10.1186/14 71-2458-8-326.
55. Schmid AA, Andersen J, Kent T, Williams LS, Damush TM. Using intervention mapping to develop and adapt a secondary stroke prevention program in Veterans Health Administration medical centers. Implement Sci. 2010;5(1):97. https://doi.org/10.1186/1748-5908-5-97.

56. van Empelen P, Kok G, Schaalma HP, Bartholomew LK. An AIDS risk reduction program for Dutch drug users: an intervention mapping approach to planning. Health Promot Pract. 2003;4(4):402-12. https://doi. org/10.1177/1524839903255421.

57. Khan KM, Weiler R, Blair SN. Prescribing exercise in primary care. BMJ. 2011; 343(jul15 3):d4141. https://doi.org/10.1136/bmj.d4141.

58. Azizan A, Justine M, Kuan CS. Effects of a behavioral program on exercise adherence and exercise self-efficacy in community-dwelling older persons. Curr Gerontol Geriatr Res. 2013;2013:282315.

59. Chase JA. Interventions to increase physical activity among older adults: a meta-analysis. Gerontologist. 2015;55(4):706-18. https://doi.org/10.1093/ geront/gnu090.

60. Chase JA. Physical activity interventions among older adults: a literature review. Res Theory Nurs Pract. 2013;27(1):53-80. https://doi.org/10.1891/1 541-6577.27.1.53.

61. Taylor AH, Cable NT, Faulkner G, Hillsdon M, Narici M, Van Der Bij AK. Physical activity and older adults: a review of health benefits and the effectiveness of interventions. J Sports Sci. 2004;22(8):703-25. https://doi. org/10.1080/02640410410001712421.

62. Bunn F, Dickinson A, Barnett-Page E, Mclnnes E, Horton K. A systematic review of older people's perceptions of facilitators and barriers to participation in falls-prevention interventions. Ageing Soc. 2008;28(4):44972. https://doi.org/10.1017/S0144686X07006861.

63. Stevens M, Lemmink KA, van Heuvelen MJ, de Jong J, Rispens P. Groningen Active Living Model (GALM): stimulating physical activity in sedentary older adults; validation of the behavioral change model. Prev Med. 2003;37(6 Pt 1):561-70. https://doi.org/10.1016/j.ypmed.2003.09.012.

64. Dye CJ, Wilcox S. Beliefs of low-income and rural older women regarding physical activity: you have to want to make your life better. Women Health. 2006;43(1):115-34. https://doi.org/10.1300/J013v43n01_07.

65. Hawley-Hague H, Horne M, Campbell M, Demack S, Skelton DA, Todd C. Multiple levels of influence on older adults' attendance and adherence to community exercise classes. Gerontologist. 2014:54(4):599-610. https://doi. org/10.1093/geront/gnt075.

66. Salisbury C, Thomas C, O'Cathain A, Rogers A, Pope C, Yardley L, et al. TElehealth in CHronic disease: mixed-methods study to develop the TECH conceptual model for intervention design and evaluation. BMJ Open. 2015; 5(2):e006448. https://doi.org/10.1136/bmjopen-2014-006448.

67. Sales $A E$, Helfrich CD. Value in development of complex interventions. Am J Manag Care. 2006;12(5):253-4.

68. Bartholomew LK, Parcel GS, Kok G, Gottieb NH, Fernandez ME. Planning health promotion programs: an intervention mapping approach. 3rd ed. San Francisco: Wiley; 2011.

69. McMillan SS, King M, Tully MP. How to use the nominal group and Delphi techniques. Int J Clin Pharm. 2016;38(3):655-62. https://doi.org/10.1007/s11 096-016-0257-x

70. Sales A, Smith J, Curran G, Kochevar L. Models, strategies, and tools. Theory in implementing evidence-based findings into health care practice. J Gen Intern Med. 2006;21(Suppl 2):S43-9.

71. Hoddinott P. A new era for intervention development studies. Pilot Feasibility Stud. 2015;36(1). https://doi.org/10.1186/s40814-015-0032-0.

\section{Publisher's Note}

Springer Nature remains neutral with regard to jurisdictional claims in published maps and institutional affiliations. 